\title{
Cytogenetic Findings of an Undifferentiated Testicular Sarcoma
}

\author{
Eiji Matsubara ${ }^{\mathrm{a}, \mathrm{e}}$, Yamochi Toshiko ${ }^{\mathrm{b}}$, Christopher A. Lumc, Yuuki Matsumoto ${ }^{\mathrm{a}}$, Ricky Kaneshiro ${ }^{\mathrm{d}}$, \\ Yuuichirou Ogawa ${ }^{a}$, Katsuyuki Saitou ${ }^{a}$, Katsuki Inoue ${ }^{a}$, Thomas Namiki ${ }^{a}$, Hidekazu Ota ${ }^{b}$, \\ Masafumi Takimoto ${ }^{\mathrm{b}}$, Makoto Shimada ${ }^{\mathrm{a}}$
}

\begin{abstract}
Primary testicular sarcomas are extremely rare. In contrast, germ cell tumors (GCTs) with sarcomatous components (SCs) that can have similar pathologic features are more frequently reported. We report a primary undifferentiated testicular sarcoma with cytogenetic analysis for amplification of $12 \mathrm{p}$. A 36-year-old male initially presented with $9.4 \mathrm{~cm}$ right testicular tumor and no metastatic disease. He was lost to follow-up but re-presented 2 years later with tumor growth to $21 \mathrm{~cm}$ and multiple pulmonary and bone metastases. Histologically, the testicular tumor revealed an undifferentiated sarcoma. Fluorescence in situ hybridization (FISH) of paraffin-embedded tissue showed no amplification of $12 p$. Gain of isochromosome $12 p(i(12 p))$ is a specific chromosomal anomaly present in most GCTs. The cytogenetic analysis indicated the possibility that the tumor was not of GCT origin. This is the first report of primary testicular undifferentiated sarcoma with cytogenetic analysis for $\mathrm{i}(12 \mathrm{p})$.
\end{abstract}

Keywords: Testicular; Intratesticular; Sarcoma; Fluorescence in situ hybridization; FISH isochromosome; 12p; Cytogenetic

\section{Introduction}

Testicular tumor is the most common solid malignancy of young men. Germ cell tumors (GCTs) represent over $95 \%$ of all these tumors. Pure seminoma accounts for $50 \%$ of all testicular

Manuscript accepted for publication October 28, 2015

a Department of Urology, Showa University Northern Yokohama Hospital, 31-5 Chigasakichuo, Tsudukiku, Yokohama, Kanagawa 244-8503, Japan

bDepartment of Pathology, Showa University, 1-5-8 Hatanodai, Shinagawaku, Tokyo 142-8666, Japan

'Department of Pathology, Queens Medical Center, 1301 Punchbowl Street, Honolulu, HI 96813, USA

dJohn A. Burns School of Medicine, University of Hawai'i, Honolulu, HI 96813, USA

${ }^{\mathrm{e} C o r r e s p o n d i n g ~ A u t h o r: ~ E i j i ~ M a t s u b a r a, ~ D e p a r t m e n t ~ o f ~ U r o l o g y, ~ S h o w a ~ U n i-~}$ versity Northern Yokohama Hospital, 31-5 Chigasakichuo, Tsudukiku, Yokohama, Kanagawa 244-8503, Japan. Email: handballer@mail.goo.ne.jp

doi: http://dx.doi.org/10.14740/jmc2356w
GCTs [1]. Non-seminomatous GCTs are yolk sac tumor, embryonal carcinoma, choriocarcinoma and teratoma. Other rare testicular tumors include lymphoma, stromal cell tumors and sarcomas. Primary testicular sarcomas are extremely rare. To our knowledge, 40 cases have reported in literature. In contrast, GCTs with sarcomatous components (SCs) are more frequently reported, accounting for 3-6\% of testicular GCTs [2]. However, it might be difficult to distinguish primary testicular sarcoma from GCTs with SC because there is some possibility that testicular sarcoma arises from GCT and secondly GCT regresses. Actually testicular chondrosarcoma which was of germ cell origin through showing isochromosome 12p (i(12p)) in metastatic sarcoma by cytogenetics was reported [3]. i(12p) has been a frequent marker of GCTs and has diagnostic significance. A lot of germ cell-related tumors represented i $(12 p)$ or other $12 p$ abnormalities by means of cytogenetic studies [4-10]. i(12p) and other forms of $12 p$ amplification are seen in the majority of testicular GCTs of adults and are present in all histological subtypes. In one report, somatic-type tumors which arose from patients who had testicular or mediastinal GCTs were analyzed by fluorescence in situ hybridization (FISH) [9]. Six of 11 cases represented $12 \mathrm{p}$ amplification and the author concluded interphase FISH for $12 p$ amplification can provide useful adjuvant diagnostic information by confirming the germ cell origin of somatic-type tumors of uncertain histogenesis. We report an extremely rare tumor, primary undifferentiated testicular sarcoma, which could be examined about $12 \mathrm{p}$ by FISH.

\section{Case Report}

A 36-year-old man presented with a 1-year history of a painless enlargement of the right testis. He did not have any urologic or constitutional symptoms. Physical examination showed no superficial lymph node swelling. An ultrasonography and computed tomography revealed a right testicular multilocular mass $9.4 \times 6.9 \mathrm{~cm}$ in size and no metastasis.

$\alpha$-fetoprotein and $\beta$-human chorionic gonadotropin (HCG- $\beta$ ) in serum were within normal limit. He was lost to follow-up but re-presented 2 years later with tumor growth to $21 \mathrm{~cm}$ and multiple pulmonary and bone metastases (parietal bone, cranial base and 12th thoracic vertebrae, right iliac bone and right thighbone). Afterward radical orchiectomy was performed, and chemotherapy was started without waiting for 
Table 1. Antibodies and Technique Used for Immunohistochemical Staining

\begin{tabular}{lllll}
\hline Antibody & Corporation & Clone & Dilution & Epitope retrieval \\
\hline Cytokeratin & DAKO & AE1/AE3 & $1: 50$ & P* \\
Desmin & Nichirei & D33 & RTU** & HIER** \\
NSE & DAKO & BBS/NC/VI-H14 & RTU & HIER \\
$\alpha-$ SMA & DAKO & 1 A4 & $1: 100$ & None \\
MIC-2 (CD99) & DAKO & $1.20 E 08$ & RTU & HIER \\
EMA & DAKO & E29 & $1: 100$ & None \\
CD30 & DAKO & Ber-H2 & RTU & HIER \\
Myoglobin & DAKO & Polyclonal & RTU & None \\
S-100 & Nichirei & Polyclonal & RTU & None \\
CK34 $\beta E 12$ & Novocastra & $34 \beta E 12$ & $1: 100$ & HIER \\
AFP & Nichirei & Polyclonal & RTU & None \\
PLAP & DAKO & 8 A9 & $1: 100$ & HIER \\
HCG- $\beta$ & Nichirei & C6405 & RTU & P \\
Calretinin & Nichirei & SP12 & RTU & HIER \\
Inhibin- $\alpha$ & Serotec & R1 & $1: 50$ & HIER \\
4-Oct & Japan Tanner Co. & MRQ-10 & $1: 100$ & HIER \\
Vimentin & DAKO & V9 & $1: 100$ & HIER \\
c-kit & Nichirei & Polyclonal & RTU & HIER \\
MSA & DAKO & HHF35 & $1: 100$ & None \\
\hline
\end{tabular}

${ }^{*} \mathrm{P}$ : enzyme digestion (proteinase $\mathrm{K}$ ) incubated at room temperature for $5 \mathrm{~min}$. ${ }^{* *} \mathrm{RTU}$ : ready to use. ${ }^{* *} \mathrm{HIER}$ : heatinduced epitope retrieval $(0.01 \mathrm{M}$ citrate buffer $\mathrm{pH} 6.0)$ incubated at $95^{\circ} \mathrm{C}$ for $40 \mathrm{~min}$.

pathological diagnosis. Combination therapy of etoposide and cisplatin which was standard chemotherapy of GCT was administrated for four courses in all. Moreover, radiation therapy was added to cranial bone, 12th thoracic vertebrae and iliac bone. Comprehensive result of treatment was partial response (bone, partial response; lung, complete response). Then he died 12 months later after surgery.

\section{Methods}

\section{Immunohistochemistry (IHC)}

Surgical specimens were fixed in buffered formalin and processed routinely. Hematoxylin and eosin stains were carried out on $4 \mu \mathrm{m}$ thick sections of formalin-fixed paraffin-embedded tissue. IHC was carried out using these antibodies: cytokeratin (AE1/AE3 and 34ßE12), EMA, desmin, vimentin, myoglobin, $\alpha$-SMA, MSA, c-kit, NSE, S-100, calretinin, CD99, CD30, AFP, HCG- $\beta$, PLAP, Oct4 and inhibin- $\alpha$, and the Envision plus detection system (Dako, Carpinteria, CA, USA). Details of antibodies are listed in Table 1.

\section{FISH}

FISH test was performed as previously described [10]. Multi- ple $4 \mu \mathrm{m}$ unstained sections were made from paraffin-embedded tissue blocks. A hematoxylin and eosin-stained slide from each specimen was examined for determination of areas for cell counting. The unstained slides were deparaffinized with three 15-min xylene washes. The slides were then hydrated using absolute ethanol washes twice for $10 \mathrm{~min}$ each. The slides then were air dried in a fume hood. Next, the slides were treated in $0.1 \mathrm{mM}$ citric acid (pH 6.0) (Zymed, Carlsbad, CA, USA) at $95{ }^{\circ} \mathrm{C}$ for $10 \mathrm{~min}$, rinsed in distilled water for $3 \mathrm{~min}$, and washed with $2 \times$ standard saline citrate (SSC) for $5 \mathrm{~min}$. The digestion of the tissue was performed by applying $0.4 \mathrm{~mL}$ of pepsin $(5 \mathrm{mg} / \mathrm{mL}$ in $0.9 \% \mathrm{NaCl}, \mathrm{pH} 1.5)$ (Sigma, St Louis, $\mathrm{MO}, \mathrm{USA}$ ) at $37^{\circ} \mathrm{C}$ for $40 \mathrm{~min}$, washed again with $2 \times \mathrm{SSC}$ for $5 \mathrm{~min}$, and air-dried.

Probes for $12 \mathrm{p}$ spectrum green and 12 centromeric spectrum orange (Vysis, Downers Grove, IL, USA) were diluted with tDenHyb2 buffer (Insitus, Albuquerque, NM, USA) in a ratio of 1:50 and 1:20, respectively. A volume of $10 \mu \mathrm{L}$ of the diluted probed was applied to the slides in the area of interest. The slide was covered with a glass coverslip and sealed with rubber cement. The slides were placed in an opaque plastic box wrapped with aluminum foil. Denaturation was achieved by incubating the slides at $80^{\circ} \mathrm{C}$ for $10 \mathrm{~min}$, after which hybridization was performed at $37^{\circ} \mathrm{C}$ for $16-18 \mathrm{~h}$. The coverslips were removed and $10 \mu \mathrm{L}$ of DAPI (Insitus, Albuquerque, NM, USA) was applied to each slide. A new coverslip was placed and the slides were examined with an Olympus IX-50 microscope (Olympus, Tokyo, Japan). Classic seminoma specimen 


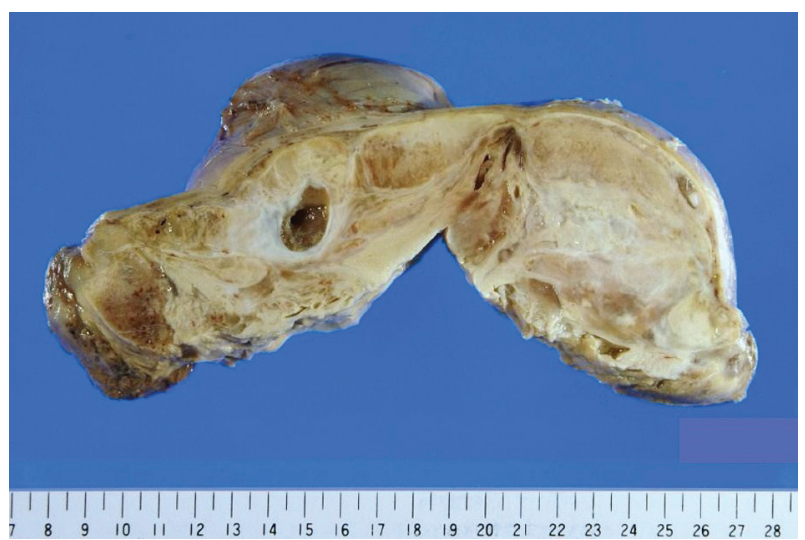

Figure 1. Gross tumor was surrounded by tunica albuginea. Cut sections showed various parts including yellowish-white solid part, myxomatous part, hemorrhage and necrotic part.

was used as a positive control. For negative controls, leiomyosarcoma specimens from patients without histories of GCTs were used. Criteria for signal detection were described previously [9]. Forty cells were counted. The green signal (12p) and orange signal (12 centromere) were counted for each tumor cell nucleus, and the average number of each signal was recorded [9]. We considered a $12 \mathrm{p} / 12$ centromeric ratio of 1.5 or greater as evidence of $12 \mathrm{p}$ amplification.

\section{Pathological and cytogenetic findings}

Tumor was measured $21 \times 20 \times 9 \mathrm{~cm}$. Gross tumor was surrounded by tunica albuginea. Cut sections showed various parts including yellowish-white solid part, myxomatous part, hemorrhage and necrotic part (Fig. 1).

Microscopically, the tumor clump lay scattered in the necrotic tissue. Tumor cells had irregularly shaped bundles of pleomorphic spindle or round cells, oval shaped, and irregularly

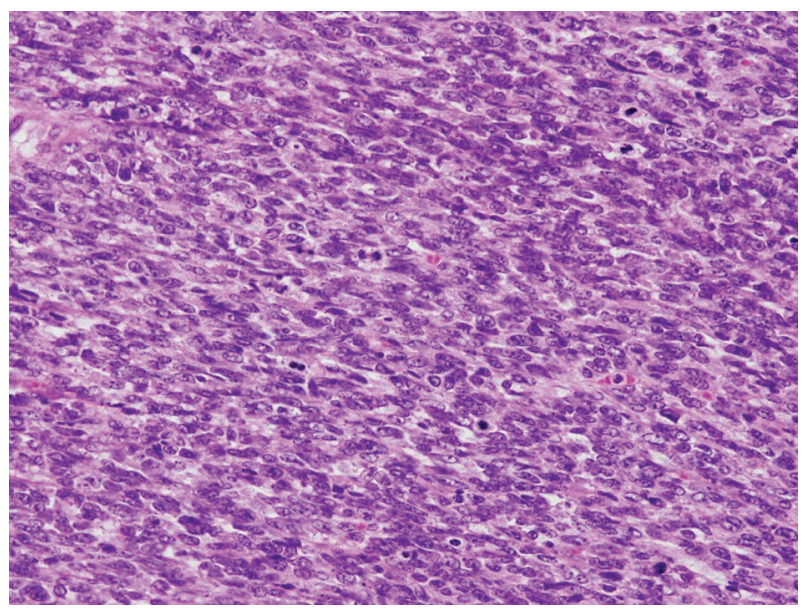

Figure 2. Tumor cells had irregularly shaped bundles of pleomorphic spindle or round cells, oval shaped, and irregularly shaped hyperchromatic nuclei with coarsely granular chromatin particles. Most of these cells had pale staining cytoplasm (H\&E).

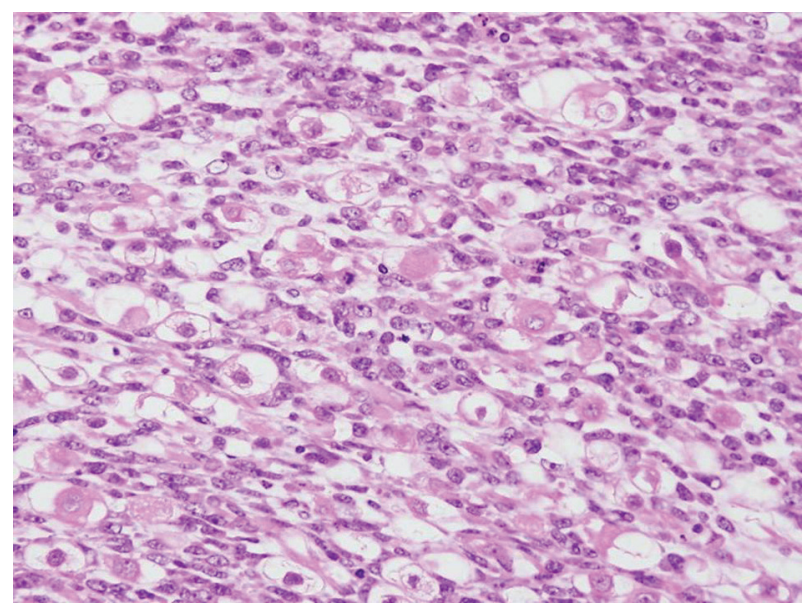

Figure 3. Isolated small number of cells had large eosinophilic or clear cytoplasm with round nuclei (H\&E).

shaped hyperchromatic nuclei with coarsely granular chromatin particles. Most of these cells had pale staining cytoplasm (Fig. 2 ). These suggest a kind of sarcoma. Isolated small number of cells had large eosinophilic or clear cytoplasm with round nuclei (Fig. 3). Spermatic cord and epididymis were remained.

Regarding IHC, vimentin was only positive, cytokeratin (AE1/AE3 and 34ßE12), EMA, c-kit, myoglobin, S-100, CD99, CD30, PLAP, AFP, HCG- $\beta$, Oct4 and inhibin- $\alpha$ were negative, NSE was partially positive, and desmin, myogenin, $\alpha-S M A$, and calretinin were very slightly positive on tumor cells. A few cells that had eosinophilic cytoplasm were stained by MSA (Fig. 4). The above was appropriate to some kind of mesenchymal tumor, not epithelium tumor and germ cell tumor, because vimentin of mesenchymal maker was positive and epithelium markers, cytokeratin and EMA, and germ cell markers, PLAP AFP HCG- $\beta$, Oct4, were negative. NSE, desmin, myogenin, $\alpha$-SMA and calretinin were too week to define diagnosis. MSA suggests differentiation to muscle. But it also did not give definitive suggestion because stained cells were very few. Accordingly, we considered this tumor was

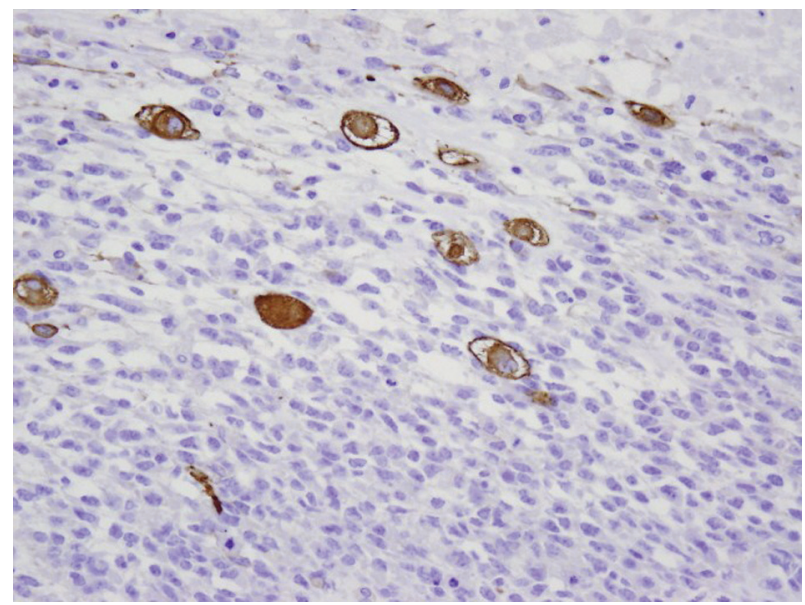

Figure 4. A few large cells that have eosinophilic or clear cytoplasm were stained by MSA. 


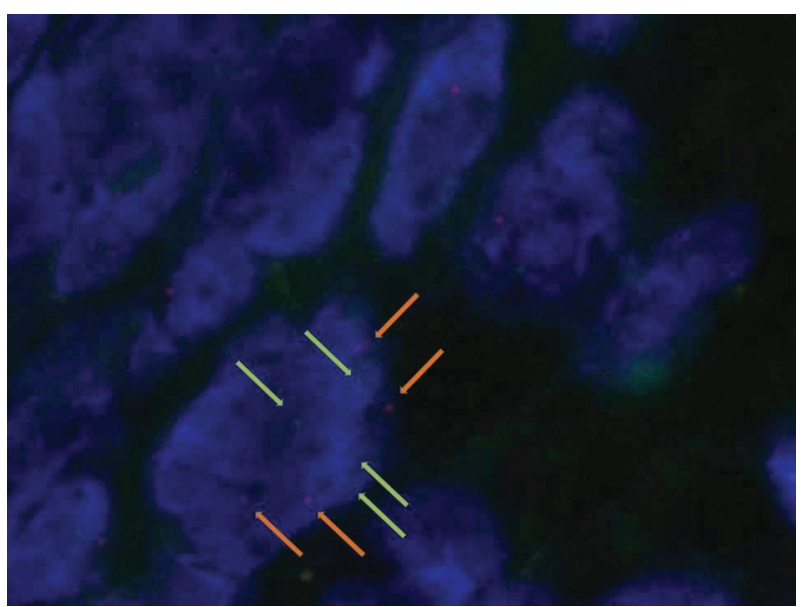

Figure 5. FISH displayed orange signals for the chromosome 12 centromeric prove (orange arrow) and green signals for $12 p$ (green arrow).

mesenchymal tumor, not of germ cell origin. IHC could not provide definitive evidence.

We added cytogenetics of FISH on paraffin-embedded tissue to detect abnormality of $12 p$. Tumor did not show amplification and deletion of $12 p$ by FISH (Fig. 5).

There is every possibility that this tumor is purely primary testicular sarcoma, not of germ cell origin. Final pathological diagnosis was primary testicular undifferentiated sarcoma.

\section{Discussion}

Primary testicular sarcoma is extremely rare. To our knowledge, 40 cases had been reported, including 15 lieomyosarcomas [11-24], seven rhabdomyosarcomas [25-30], five spindle sarcomas [31-34], four osteosarcomas [35-38], two fibrosarcomas [36, 39], two pleomorphicsarcomas [33], two liposarcomas [33, 40], one chondrosarcoma [3], one kaposi sarcoma [41] and one undifferentiated sarcoma [13].

On the other hand, testicular GCTs with SC were relatively often reported, accounting for 3-6\% of testicular GCTs [2]. It is said that excluding these cases is important to diagnose primary testicular sarcoma because primary testicular sarcoma has better prognosis than testicular GCTs with SC [13]. In only six cases of 41 cases (15\%) including our case, they had metastasis and/or recurrence in a term of observation after treatment (9 weeks to 21 years) [22, 28, 30, 39]. However, two cases of these six cases were considered that tumors arose from tunica and epididymis and they might be cases that should be distinguished from primary testicular tumors [30]. Treatment outcome was three deaths (7\%) including one rhabdomyosarcoma, one fibrosarcoma and our undifferentiated sarcoma [30, 39]. Whereas Guo et al reported $74 \%$ cases of testicular GCTs with SC had metastases when diagnosed and 30\% of the patients died of disease (5 months to 20 years) [2]. Primary testicular sarcoma has apparent indolent natural history compared with GCTs with SC.

There is a problem about diagnosis between primary testicular sarcoma and testicular GCTs with SC. GCTs may of- ten regress. Hence, there is possibility that apparent primary testicular sarcoma arises from GCT. Actually testicular chondrosarcoma which was ascertained to be of germ cell origin by cytogenetic analysis was reported [12]. Therefore, we performed cytogenetics in order to judge if they were of germ cell origin or not. There are many studies which have evaluated $12 \mathrm{p}$ abnormalities in testicular GCTs. Rodriguez et al reported cytogenetic analysis of 120 cases of GCTs [4]. In 90 of 120 cases, $\mathrm{i}(12 \mathrm{p})$ was seen in $86 \%$ of seminomas, $89 \%$ of teratomas, $83 \%$ of embryonal carcinomas and $100 \%$ of yolk sac tumors. Bosl et al reported 101 of 171 cases $(59 \%)$ of germ cell tumors yielded i(12p) [5]. Furthermore, FISH detected i(12p) in 47 of 47 cases (100\%) in this study. Moreover, studies using FISH have been performed and high positive rate was shown. Smolarek et al evaluated 11 primary GCTs and 16 metastatic GCTs using FISH [6]. 12p overexpression was found in all 27 cases $(100 \%)$. Pienkowska-Grela et al analyzed 15 testicular GCTs using FISH [8]. 12p abnormalities were seen in 14 cases $(93 \%)$. Korski et al reported that $12 \mathrm{p}$ abnormalities were identified in 22 of 23 (96\%) primary mediastinal seminomas [42]. Approximately conventional cytogenetics revealed i $(12 p)$ in $60-80 \%$ GCTs and FISH analyses gave higher positive rate of $93-100 \%$ of $12 p$ amplification or anomaly.

Interphase FISH studies have recently been used to distinguish germ cell origin or not by identification of $12 p$ abnormalities in somatic tumors. Kernek et al proved somatic-type metastatic tumors were originally from GCT at different parts by confirming i(12p) using FISH [9]. Motzer et al studied the cytogenetic features of secondary somatic components in 12 cases of GCT [7]. It showed that 10 cases represented i(12p) and one case represented $12 p$ deletion. Kernek et al concluded FISH analysis of $\mathrm{i}(12 \mathrm{p})$ is useful for establishing germ cell origin of metastatic tumors [9]. Actually Korski et al reported a case of primary testicular GCT with rhabdomyosarcoma metastases [42]. The i(12p) in metastatic rhabdomyosarcoma by FISH proved that this metastatic sarcoma was of germ cell origin [42].

No amplification and anomaly of $12 p$ were seen in our case. Therefore, this tumor was not considered to arise from GCT and there is every possibility that this tumor is truly primary testicular sarcoma not of germ cell origin. This is the first case of primary testicular sarcoma which does not represent $12 p$ anomaly by cytogenetics.

If this sarcoma is pure primary testicular sarcoma, good prognosis is expected because most testicular sarcomas represented good prognosis. However, this case had lung and widespread bone metastases 2 years later from first visit. This testicular sarcoma had no metastasis at the time of first evaluation. Suppose radical orchiectomy was performed, he might have been cured. Accordingly it is not clear about prognosis.

In order to research testicular sarcoma, testicular sarcoma should be examined about chromosome to distinguish if they were of germ cell origin or not. If possible, FISH method is better than conventional method in respect of sensibility.

\section{Grant Support}

None. 


\section{References}

1. Khan O, Protheroe A. Testis cancer. Postgrad Med J. 2007;83(984):624-632.

2. Guo CC, Punar M, Contreras AL, Tu SM, Pisters L, Tamboli P, Czerniak B. Testicular germ cell tumors with sarcomatous components: an analysis of 33 cases. Am J Surg Pathol. 2009;33(8):1173-1178.

3. Fuzesi L, Rixen H, Kirschner-Hermanns R. Cytogenetic findings in a metastasizing primary testicular chondrosarcoma. Am J Surg Pathol. 1993;17(7):738-742.

4. Rodriguez E, Mathew S, Reuter V, Ilson DH, Bosl GJ, Chaganti RS. Cytogenetic analysis of 124 prospectively ascertained male germ cell tumors. Cancer Res. 1992;52(8):2285-2291.

5. Bosl GJ, Ilson DH, Rodriguez E, Motzer RJ, Reuter VE, Chaganti RS. Clinical relevance of the $\mathrm{i}(12 \mathrm{p})$ marker chromosome in germ cell tumors. J Natl Cancer Inst. 1994;86(5):349-355.

6. Smolarek TA, Blough RI, Foster RS, Ulbright TM, Palmer CG, Heerema NA. Identification of multiple chromosome 12 abnormalities in human testicular germ cell tumors by two-color fluorescence in situ hybridization (FISH). Genes Chromosomes Cancer. 1995;14(4):252-258.

7. Motzer RJ, Amsterdam A, Prieto V, Sheinfeld J, Murty VV, Mazumdar M, Bosl GJ, et al. Teratoma with malignant transformation: diverse malignant histologies arising in men with germ cell tumors. J Urol. 1998;159(1):133138.

8. Pienkowska-Grela B, Grygalewicz B, Bregula U. Overrepresentation of the short arm of chromosome 12 in seminoma and nonseminoma groups of testicular germ cell tumors. Cancer Genet Cytogenet. 2002;134(2):102-108.

9. Kernek KM, Brunelli M, Ulbright TM, Eble JN, Martignoni G, Zhang S, Michael H, et al. Fluorescence in situ hybridization analysis of chromosome $12 p$ in paraffinembedded tissue is useful for establishing germ cell origin of metastatic tumors. Mod Pathol. 2004;17(11):13091313.

10. Sung MT, Maclennan GT, Lopez-Beltran A, Zhang S, Montironi R, Cheng L. Primary mediastinal seminoma: a comprehensive assessment integrated with histology, immunohistochemistry, and fluorescence in situ hybridization for chromosome 12p abnormalities in 23 cases. Am J Surg Pathol. 2008;32(1):146-155.

11. Yachia D, Auslaender L. Primary leiomyosarcoma of the testis. J Urol. 1989;141(4):955-956.

12. Pellice C, Sabate M, Combalia, Ribas E, Cosme M. [Leiomyosarcoma of the testis]. J Urol (Paris). 1994;100(1):4648.

13. Washecka RM, Mariani AJ, Zuna RE, Honda SA, Chong CD. Primary intratesticular sarcoma. Immunohistochemical ultrastructural and DNA flow cytometric study of three cases with a review of the literature. Cancer. 1996;77(8):1524-1528.

14. Froehner M, Fischer R, Leike S, Hakenberg OW, Noack B, Wirth MP. Intratesticular leiomyosarcoma in a young man after high dose doping with Oral-Turinabol: a case report. Cancer. 1999;86(8):1571-1575.

15. Hachi H, Bougtab A, Amhajji R, Otmany F, al Bouzidi A, Laalou L, Bellabas M, et al. [A case report of testicular leiomyosarcoma]. Med Trop (Mars). 2002;62(5):531533.

16. Ali Y, Kehinde EO, Makar R, Al-Awadi KA, Anim JT. Leiomyosarcoma complicating chronic inflammation of the testis. Med Princ Pract. 2002;11(3):157-160.

17. Sattary M, Hazraty B, Bagche Saraii M. Primary pure testicular low-grade leiomyosarcoma. IJMS. 2003;28:48-50.

18. Wakhlu A, Chaudhary A. Massive leiomyosarcoma of the testis in an infant. J Pediatr Surg. 2004;39(7):e16-17.

19. Singh R, Chandra A, O'Brien TS. Primary intratesticular leiomyosarcoma in a mixed race man: a case report. J Clin Pathol. 2004;57(12):1319-1320.

20. Takizawa A, Miura T, Fujinami K, Kawakami S, Osada Y, Kameda Y. Primary testicular leiomyosarcoma. Int J Urol. 2005;12(6):596-598.

21. Kumar M, Patne SC, Kumar S, Shukla VK. Primary highgrade testicular leiomyosarcoma. Indian J Pathol Microbiol. 2009;52(1):91-93.

22. Yoshimine S, Kono H, Nakagawa K, Kikuchi E, Miyajima A, Kameyama K, Mukai M, et al. Primary intratesticular leiomyosarcoma. Can Urol Assoc J. 2009;3(6):E74-76.

23. Raspollini MR, Stomaci N, Ringressi A, Franchi A. Primitive testicular leiomyosarcoma. Pathol Oncol Res. 2010;16(2):177-179.

24. Tobe M, Tanda H, Kato S, Onishi S, Nakajima H, Nitta T, Akagashi K, et al. [Primary testicular leiomyosarcoma]. Hinyokika Kiyo. 2010;56(9):535-538.

25. Davis A. Rhabdomyosarcoma of the testicle. J Urol. 1962;82:148-158.

26. Ravich L, Lerman PH, Drabkin JW, Foltin E. Pure testicular rhabdomyosarcoma. J Urol. 1965;94(5):596-599.

27. Tripathi VN, Dick VS. Primary sarcoma of the urogenital system in adults. J Urol. 1969;101(6):898-904.

28. Jungling MJ, Culp DA. Case report of embryonal rhabdomyosarcoma of the testis with an 8-year survival. J Urol. 1975;114(2):313-315.

29. Kumar PV, Khezri AA. Pure testicular rhabdomyosarcoma. Br J Urol. 1987;59(3):282.

30. Stewart LH, Lioe TF, Johnston SR. Thirty-year review of intrascrotal rhabdomyosarcoma. $\mathrm{Br} \mathrm{J}$ Urol. 1991;68(4):418-420.

31. Brady EA, Jarrett W, Backwinkel KD. Bilateral Testicular Tumors: Spindle Cell Sarcoma and Seminoma; Case Report. J Urol. 1963;90:215-219.

32. Allaway M, Nseyo UO, Kandzari SJ. Primary testicular sarcoma. J Urol. 2000;163(6):1871.

33. Chandra A, Baruah RK, Ramanujam, Rajalakshmi KR, Sagar G, Vishwanathan P, Raman. Primary intratesticular sarcoma. Indian J Med Sci. 2001;55(8):421-428.

34. Schoeneich G, Oehlmann U, Gustmann C, Albers P. Primary intratesticular sarcoma of the testis: a rare manifestation of testicular cancer. Scand J Urol Nephrol. 2005;39(3):249-250.

35. Mathew T, Prabhakaran K. Osteosarcoma of the testis. Arch Pathol Lab Med. 1981;105(1):38-39.

36. Zukerberg LR, Young RH. Primary testicular sarcoma: a 
report of two cases. Hum Pathol. 1990;21(9):932-935.

37. Lee JS, Choi YD, Choi C. Primary testicular osteosarcoma with hydrocele. Virchows Arch. 2004;445(2):210213.

38. Tazi H, Karmouni T, Ouali M, Koutani A, Hachimi M, Lakrissa A. Osteosarcoma of the testis. Int J Urol. 2006;13(3):323-324.

39. Val-Bernal JF, Azcarretazabal T, Torio B, Mayorga M. Primary pure intratesticular fibrosarcoma. Pathol Int. 1999;49(2):185-189.
40. Peterson AC, Porter M, Porter J. Adult testicular sarcoma: presentation, evaluation, and treatment. Urology. 2002;59(2):294-295.

41. Kneale BJ, Bishop NL, Britton JP. Kaposi's sarcoma of the testis. Br J Urol. 1993;72(1):116-117.

42. Korski K, Breborowicz D, Filas V, Breborowicz J, Grygalewicz B, Pienkowska-Grela B. A case of primary testicular germ cell tumor with rhabdomyosarcoma metastases as an example of applying the FISH method to diagnostic pathology. APMIS. 2007;115(11):1296-1301. 